International Journal of Biological Research, $2(1)(2014) 23-25$
International Journal of Biological Research
Journal home page: $\begin{gathered}\text { www.sciencepubco.com/index.php/IJBR } \\ \text { doi: } 10.14419 / \text { ijbr.v2il.2493 } \\ \text { Research Paper }\end{gathered}$

\title{
Characterization of vibrio cholerae isolated from human Diarrhoea in mymensingh, Bangladesh
}

\author{
Md. Rahamat Ali ${ }^{1 *}$, Md. Shahidur Rahman Khan ${ }^{2}$, Most. Arifa Khatun ${ }^{3}$, M. Shah Alam ${ }^{4}$, A.K.M. Mostafa \\ Anower ${ }^{5}$, Mohammad Enamul Hoque Kayesh ${ }^{5}$ \\ ${ }^{1}$ Veterinary Surgeon, Upazilla Livestock Office, Razarhat, Kurigram \\ ${ }^{2}$ Professor, Department of Microbiology and Hygiene, Bangladesh Agricultural University \\ ${ }^{3}$ Department of Surgery and Obstetrics, Bangladesh Agricultural University \\ ${ }^{4}$ Lecturer, Department of Pathology and Parasitology, Patuakhali Science and Technology University \\ ${ }^{5}$ Assistant Professor, Department of Microbiology, Patuakhali Science and Technology University \\ *Corresponding author E-mail: mehkayesh@pstu.ac.bd
}

\begin{abstract}
Diarrhoeal diseases are one of the top five causes of mortality in all age groups in Bangladesh. An investigation was carried out with the aim of focusing the isolation and characterization of Vibrio cholerae from diarrhoeal stools of human in Mymensingh, Bangladesh. A total of 42 rectal swab samples were aseptically collected from human. Vibrio cholerae was isolated from diarrhoeal stools of human by cultural and biochemical examinations and susceptibility of the isolated Vibrio cholerae to different antibacterial agents was performed by Disc diffusion test. Out of 42 samples, 8 were found to be positive for Vibrio cholerae. The overall prevalence of Vibrio cholerae was $19.05 \%$. The antibiotic sensitivity pattern demonstrated that Vibrio cholerae isolates were highly sensitive to Polymixin B, ciprofloxacin and co-trimoxazole; moderately sensitive to cephalexin and nalidixic acid; less sensitive to erythromycin; and resistant to amoxicillin. This study suggested that there was remarkable prevalence of Vibrio cholerae in human diarrhoea and Polymixin B, ciprofloxacin and co-trimoxazole could be used for treating the patients with diarrhoea caused by Vibrio cholerae.
\end{abstract}

Keywords: Characterization, Vibrio Cholerae, Human, Diarrhoea.

\section{Introduction}

Vibrio cholerae (V. cholerae) is a gram negative straight, single, rigid comma-shaped bacterium with a polar flagellum that causes cholera in humans (Ryan and Ray, 2004; Faruque and Nair, 2008). The causative agent of cholera is classified into two serotypes on the basis of the somatic "O" surface antigen: $\mathrm{O} 1$ and non $\mathrm{O} 1$ (Chatterjee and Maiti, 1984). V. cholerae was first isolated as the cause of cholera by Italian anatomist Filippo Pacini in 1854, but his discovery was not widely known until Robert Koch, working independently thirty years later, publicized the knowledge and the means of fighting the disease (Howard-Jones, 1984; Bentivoglio and Pacini, 1995). Cholera is a gastroenteritis infections caused by enterotoxin-producing V. cholerae (Faruque and Nair, 2008). Vibrio species account for a significant proportion of human infections from the consumption of raw or undercooked shellfish. Waste-stabilization ponds are possible reservoirs of cholera. It has caused many epidemics and pandemics of cholera resulting in millions of deaths (Albert et al., 1993; Kaper et al., 1995). Transmission of V. cholerae to humans occurs through eating or drinking contaminated food or water. Aquatic environments can serve as good reservoirs of the bacteria (Islam et al., 1993). The primary symptoms of cholera are profuse, painless diarrhoea and vomiting of clear fluid (Sack et al., 2004). These symptoms usually start suddenly, half a day to five days after ingestion of the bacteria ((Azman et al., 2012). The diarrhoea is frequently described as "rice water" in nature and may have a fishy odor. An untreated person with cholera may produce 10-20 litres of diarrhoea a day. If the severe diarrhoea is not treated with intravenous rehydration, it can result in life-threatening dehydration and electrolyte imbalances (Sack et al., 2004).

In Bangladesh, diarrhoeal diseases are one of the top five causes of mortality in all age groups combined, causing 68,000 deaths in a year (World Health Organization, 2006). Ten percent of Bangladeshi children aged less than 5 years reportedly suffered from at least one episode of diarrhoea, according to the Bangladesh Demographic and Health Survey 2007. During the summer of 2007, Bangladesh suffered from one of the worst diarrhoeal disease outbreaks in the recent history. Severe torrential rains led to devastating floods, submerging some 34 of the 64 districts in Bangladesh, resulting in a major outbreak of diarrhoea (Khan et al., 2007). Antimicrobial therapy still plays a critical role in diarrhoea caused by V. cholerae because it can reduce the volume of diarrhoea as well as shorten the duration of symptoms and the excretion of vibrios in the stool. The ciprofloxacin-trimethoprim (Cp-Tm) combination showed synergistic and additive effects against $\mathrm{V}$. cholerae (Mandal et al., 2009).

Bangladesh is a densely populated country and diarrhoea is very common among the people of Bangladesh. Most of the people in the rural and urban area are living in unhygienic conditions. Drinking water supplies are not good. As a result of poor hygiene and lack of potable water supplies many people suffer from diarrhoea. The causes of diarrhoea are many. So, the study was undertaken to isolate and characterize V. cholerae from diarrhoeal stools of human using cultural, morphological and biochemical examinations to know the prevalence of diarrhoeal episode in Bangladesh 
caused by V. cholerae as well as to know the antibiotic sensitivity profile of the isolates.

\section{Materials and Methods}

\subsection{Collection of samples}

A total of 42 rectal swab samples were aseptically collected (thirty five from SK Hospital and 7 from Bangladesh Agricultural University (BAU) Health Centre, Mymensingh, Bangladesh) from human. Collected swab samples were inoculated into test tubes containing freshly prepared sterile nutrient broth (NB) and carried to the laboratory for the characterization of $\mathrm{V}$. cholerae.

\subsection{Isolation and characterization}

Isolation of $\mathrm{V}$. cholerae from the samples were carried out by culturing the samples on Nutrient agar (NA), Blood agar (BA), MacConkey (MC) agar and Thiosulfate citrate bile salts sucrose (TCBS) agar plates. The inoculated plates were incubated at $37{ }^{\circ} \mathrm{C}$ for 24-48 hours. TCBS agar containing characteristic colonies of V. cholerae were selected for subculturing in order to obtain a pure culture of the organisms. The organisms thus obtained as pure culture were selected for further studies (Kaper et al, 1995). Identification of the $\mathrm{V}$. cholerae from the pure culture was carried out based on their colony characteristics, Gram staining reaction, haemolysis pattern and motility test (Barrow and Feltham, 1993; Cheesbrough, 1985). Biochemical characterizations of the isolates were performed with sugar fermentation test, Triple sugar iron agar slant reaction, Methyl Red test (MR) and Voges-Proskauer test (VP), indole test, oxidase test and catalase test (Cheesbrough, 1985; Pedersen et al., 1999).

Susceptibility of the isolated V. cholerae to different antibacterial agents was performed by Disc diffusion test (Bauer et al., 1966). This method allowed the rapid determination of in vitro efficacy of an antibiotic by measuring the diameter of the zone of inhibition, which results from diffusion of the agent into the medium surrounding the disc. Seven commercially available antibacterial agents (Hi-Media Laboratories, Bombay, India) were used for this purpose. The name of these antibacterial agents, their concentration per disc and the diameter of zone of inhibition that was used to interpret the data are presented in Table 1.

Table 1: Antibacterial Agents Used For the Determination of Antibiotic Sensitivity Pattern

\begin{tabular}{lllll}
\hline \multirow{2}{*}{$\begin{array}{l}\text { Antibacterial } \\
\text { Agents }\end{array}$} & $\begin{array}{l}\text { Concentration } \\
(\mu \mathrm{g} / \mathrm{disc})\end{array}$ & \multicolumn{3}{l}{$\begin{array}{l}\text { Interpretation of results } \\
\text { (Zone Diameter in mm) }\end{array}$} \\
\cline { 3 - 5 } & $\mathrm{R}$ & $\mathrm{I}$ & $\mathrm{S}$ \\
\hline Co-trimoxazole & $25 \mu \mathrm{g}$ & $\leq 14$ & $15-18$ & $\geq 19$ \\
Erythromycin & $10 \mu \mathrm{g}$ & $\leq 11$ & $12-14$ & $\geq 15$ \\
Amoxicillin & $10 \mu \mathrm{g}$ & $\leq 11$ & $12-14$ & $\geq 15$ \\
Cephalexin & $30 \mu \mathrm{g}$ & $\leq 11$ & $12-15$ & $\geq 17$ \\
Ciprofloxacin & $5 \mu \mathrm{g}$ & $\leq 15$ & $16-20$ & $\geq 21$ \\
Nalidixic acid & $30 \mu \mathrm{g}$ & $\leq 14$ & $15-17$ & $\geq 18$ \\
Polymixin B & $15 \mu \mathrm{g}$ & $\leq 12$ & $13-15$ & $\geq 16$ \\
\hline
\end{tabular}

$\mu \mathrm{g}=$ Microgram; $\mathrm{mm}=$ Millimeter; $\mathrm{S}=$ Sensitive; $\mathrm{I}=$ intermediately sensitive; $\mathrm{R}=$ Resistant

\section{Results}

V. cholerae was isolated and identified from the suspected stool samples after cultivation on NA, BA, MC and TCBS agar. All isolates produced yellow, smooth and shiny colonies on thiosulfate citrate bile salts sucrose agar. In stab culture on triple sugar iron agar slant, all the isolates produced an acid (yellow) slant and acid (yellow) butt and no gas. The results of colony characteristics on NA, BA, MC and TCBS agar are presented in Table 2.

Table 2: Cultural Characteristics of the Isolated Vibrio Cholerae on Different Media

\begin{tabular}{llll}
\hline NA & BA & MC agar & TCBS agar \\
\hline $\begin{array}{l}\text { Growth of trans- } \\
\text { lucent, smooth, } \\
\text { shiny, colonies }\end{array}$ & $\begin{array}{l}\text { Colonies were } \\
\text { surrounded by a }\end{array}$ & $\begin{array}{l}\text { Colorless to } \\
\text { light pink colo- }\end{array}$ & $\begin{array}{l}\text { Yellow, shiny } \\
\text { colonies, 2 to }\end{array}$ \\
& nies, 1 to 3 mm & $\begin{array}{l}4 \mathrm{~mm} \text { in di- } \\
\text { in diameter }\end{array}$ & ameter \\
\hline
\end{tabular}

$\mathrm{NA}=$ Nutrient agar; $\mathrm{BA}=$ Blood agar; $\mathrm{MC}=$ MacConkey; and TCBS $=$ Thiosulfate Citrate bile Salt Sucrose

In Gram's staining technique the V. cholerae isolates exhibited Gram negative, small curved rod shaped appearance under microscope. The isolates were found non-motile in distilled water but motile in the peptone water. Morphology, staining and motility characteristics of the isolates are given in Table 3.

Table 3: Morphology, Staining and Motility Characteristics of Isolated Bacteria

\begin{tabular}{lllll}
\hline $\begin{array}{l}\text { Name of } \\
\text { isolates }\end{array}$ & Shape & Arrangement & $\begin{array}{l}\text { Gram's } \\
\text { staining } \\
\text { reaction }\end{array}$ & $\begin{array}{l}\text { Motility } \\
\text { characters }\end{array}$ \\
\hline $\begin{array}{l}\text { Vibrio } \\
\text { cholerae }\end{array}$ & $\begin{array}{l}\text { Curved } \\
\text { rods }\end{array}$ & $\begin{array}{l}\text { Single or } \\
\text { paired }\end{array}$ & $\begin{array}{l}\text { Gram } \\
\text { negative }\end{array}$ & $\begin{array}{l}\text { Motile in distilled } \\
\text { water and non- } \\
\text { motile in peptone } \\
\text { water }\end{array}$ \\
\hline
\end{tabular}

All isolates fermented dextrose, maltose, sucrose and mannitol with production of acid only but did not ferment lactose. Furthermore, all the isolates showed methyl red, indole, catalase and oxidase test positive but Voges-Proskauer test negative. Biochemical characteristics of the isolated V. cholerae are presented in Table 4. In this study, out of 42 different samples 8 were identified as positive for V. cholerae and no samples collected from BAU Health Centre were found as positive for V. cholerae. The overall prevalence of V. cholerae was $19.04 \%$. The results of isolation of V. cholerae from diarrheic human stools are shown in Table 5.

Table 4: Biochemical Characteristics of the Isolated Bacteria

\begin{tabular}{|c|c|c|c|c|c|c|c|c|c|c|}
\hline \multicolumn{5}{|c|}{ Carbohydrate fermentation tests using } & \multirow{2}{*}{ MR Test } & \multirow{2}{*}{ VP Test } & \multirow{2}{*}{ Indole Test } & \multirow{2}{*}{ Catalase Test } & \multirow{2}{*}{ Oxidase Test } & \multirow{2}{*}{ Interpretation } \\
\hline DX & ML & $\mathrm{L}$ & SU & $\mathrm{MN}$ & & & & & & \\
\hline A & A & -ve & A & A & $+\mathrm{ve}$ & -ve & $+\mathrm{ve}$ & $+\mathrm{ve}$ & $+\mathrm{ve}$ & V. cholerae \\
\hline
\end{tabular}


Table 5: Isolation of Vibrio Cholerae from Human Diarrheic Feces Sam-

\begin{tabular}{|c|c|c|c|}
\hline $\begin{array}{l}\text { Source of Sam- } \\
\text { ples }\end{array}$ & $\begin{array}{l}\text { No. of } \\
\text { sample } \\
\text { collected }\end{array}$ & $\begin{array}{l}\text { No. of sample } \\
\text { positive for } \\
\text { V. cholerae }\end{array}$ & $\begin{array}{l}\text { Prevalence of } \\
\text { V. cholerae }\end{array}$ \\
\hline $\begin{array}{l}\text { SK Hospital, } \\
\text { Mymensingh } \\
\text { BAU Health }\end{array}$ & 35 & 8 & $22.89 \%$ \\
\hline $\begin{array}{l}\text { Care Centre, } \\
\text { Mymensingh }\end{array}$ & 7 & 0 & $00.00 \%$ \\
\hline Total & 42 & 8 & $19.05 \%$ \\
\hline
\end{tabular}

In vitro antibiotic sensitivity pattern of isolated V. cholerae was performed against 7 commonly used antibiotics belonging to different groups. After incubation, plates were examined and diameters of the zone of inhibition were measured and antibacterial sensitivity was expressed by highly sensitive $(+++)$, moderately sensitive $(++)$, less sensitive $(+)$ and resistant $(-)$. The results of antibiotic sensitivity of the isolates are given in Table 6 .

Table 6: Results of antibiotic sensitivity test using various isolates of Vibrio cholerae

\begin{tabular}{lllllllll}
\hline $\begin{array}{l}\text { Total no. of iso- } \\
\text { lates }\end{array}$ & \multicolumn{9}{l}{ Antibiotics discs used } \\
CT & ER & AX & CP & CI & NA & PB \\
\hline 8 & +++ & + & - & ++ & $\begin{array}{l}+ \\
++\end{array}$ & ++ & +++ \\
\hline
\end{tabular}

$\mathrm{CT}=$ Co-trimoxazole, $\mathrm{ER}=$ Erythromycin, $\mathrm{AX}=$ Amoxicillin, $\mathrm{CP}=$ Cephalexin, $\mathrm{CI}=$ Ciprofloxacin, $\mathrm{NA}=$ Nalidixic acid, $\mathrm{PB}=$ Polymixin $\mathrm{B}$; $+++=$ highly sensitive,$++=$ moderately sensitive,$+=$ Less sensitive,,$=$ Resistan

\section{Discussion}

In this study, the organisms produced yellow and shiny colonies of 2 to $4 \mathrm{~mm}$ in diameter on TCBS agar and colorless colonies on MC agar which became pink after prolonged incubation and on BA there was production of colorless colony with haemolysis. The colony characteristics of $\mathrm{V}$. cholerae observed on BA, MC and TCBS agar were also found by other authors (Choopun et al., 2002; Khan et al., 2007). In Gram's staining, the morphological characteristics of the isolated V. cholerae exhibited Gram negative, small curved rod shaped appearance under microscope (Faruque and Nair, 2008). In motility test, the isolates were found motile in alkaline peptone water and non-motile in distilled water which was in conformity with other results (Kaper et al., 1995). In sugar fermentation test, V. cholerae isolates fermented dextrose, maltose and mannitol but not lactose and produced acid only, which was similar to the findings of other authors (Choopun et al., 2002). In this study, all the isolates were found positive to indole test, catalase test, oxidase test and Methyl Red test and negative to VogesProskauer test. These findings are in conformity with earlier reports by other authors (Kaper et al., 1995).

The antibiotic sensitivity study revealed that all the isolated V. cholerae were highly sensitive to Polymixin B, ciprofloxacin and co-trimoxazole; moderately sensitive to nalidixic acid and cephalexin; less sensitive to Erythromycin; and resistant to Amoxicillin. These findings are in agreement with the findings of earlier reports (Sack et al., 2006). The antibacterial resistance observed in the V. cholerae isolates might be due to indiscriminate use of those antibacterial agents in field condition in study areas and/or rapid chromosomal mutation and presence of specific plasmid DNA. Antibiotic susceptibility profile will help physicians to select appropriate antibiotics for the treatment of diarrhoea caused by $\mathrm{V}$. cholerae.

\section{Conclusion}

Our study showed that the diarrhoeal episodes in Bangladesh caused by V. cholerae are remarkable and the overall prevalence of V. cholerae in study area was $19.05 \%$. It was also found that V. cholerae isolates were highly sensitive to Polymixin B, ciprofloxacin and co-trimoxazole and resistant to amoxicillin.

\section{References}

[1] Albert MJ, Siddique AK, Islam MS, Faruque AS, Ansaruzzaman M, Faruque SM and Sack RB.1993, Large outbreak of clinical cholera due to Vibrio cholerae non-O1 in Bangladesh, The Lancet, 341:704.

[2] Azman AS, Rudolph KE, Cummings DAT, Lessler J. 2012. "The incubation period of cholera: A systematic review", Journal of Infection, 66: 432-438.

[3] Barrow GI and RKA Feltham. 1993, Cowan and Steel's manual for the identification of medical bacteria, 3rd ed. Cambridge University Press, Cambridge, Mel-bourne, Australia.

[4] Bauer AW, Kirby WM, Sherris JC, Turck M. 1966, Antibiotic susceptibility testing by a standardized single disc method, American Journal of Clinical Pathology, 45:493-496.

[5] Bentivoglio M and Pacini P. 1995, "Filippo Pacini: a determined observer", Brain Research Bulletin, 38: 161-165.

[6] Chatterjee SN, Maiti M. 1984, Vibriophages and Vibriocins: physical, chemical and biological properties, Advanced Virus Research, 29: 263-312.

[7] Cheesbrough M. 1985, Medical laboratory manual for tropical countries, Vol. II: Microbiology, 400-480.

[8] Choopun N, Louis V, Huq A and Colwell RR. 2002, Simple Procedure for Rapid Identification of Vibrio cholerae from the Aquatic Environment, Applied and Environmental Microbiology, 68: 995- 998.

[9] Faruque SM and Nair GB. 2008, Vibrio cholerae: Genomics and Molecular Biology, Caister Academic Press. Norfolk, UK.

[10]Howard-Jones N. 1984, Robert Koch and the cholera vibrio: a centenary, British Medical Journal. 288: 379-381.

[11]Islam MS, Drasar BS and Sack RB. 1993, The aquatic environment as a reservoir of Vibrio cholerae: a review, Journal of Diarrhoeal Disease Research, 11:197-206.

[12] Kaper JB, Morris JG Jr and Levine MM.1995, Cholera. Clinical Microbiology Review, 8:48-86.

[13] Khan AW, Hossain SJ and Uddin SN. 2007, Isolation, identification and determination of antibiotic susceptibility of Vibrio parahaemolyticus from shrimp at Khulna region of Bangladesh, $\mathrm{Re}-$ search Journal of Microbiology, 2: 216-227.

[14]Mandal S, Pal NK, Chowdhury IH and Debmandal M. 2009, Antibacterial activity of ciprofloxacin and trimethoprim, alone and in combinittion, against Vibrio cholerae O1 biotype El Tor serotype Ogawa isolates, Polish Journal of Microbiology, 58:57-60.

[15]Pedersen K, Grisez L, van Houdt R, Tiainen T, Ollevier F and Larsen JL .1999, Extended Serotyping Scheme for Vibrio anguillarum with the Definition and Characterization of Seven Provisional $O$ Serogroups, Current Microbiology, 38: 183-189.

[16]Ryan KJ and Ray CG. 2004, Sherris Medical Microbiology. 4th ed. McGraw Hill, 376- 377.

[17]Sack DA, Sack RB and Chaignat CL. 2006, Getting serious about cholera, The New England Journal of Medicine, 355: 649-651.

[18] Sack DA, Sack RB, Nair GB and Siddique AK. 2004, Cholera, Lancet, 363: 223-233

[19]World Health Organization. 2006, Mortality country fact sheet 2006, Geneva: World Health Organization. 